\title{
Imagens constituindo narrativas: fotografia, saúde coletiva e construção da memória na escrita da história local*
}

\author{
Narratives created by images: photography, collective health and \\ the construction of memory in the writing of local history
}

\section{Luís Reznik}

Pontifícia Universidade Católica do Rio de Janeiro; Universidade do Estado do Rio de Janeiro. Rua Henrique Fleiuss, 278 20521-260 Rio de Janeiro - RJ Brasil

lreznik@rdc.puc-rio.br

\section{Marcelo da Silva Araújo}

Secretaria Municipal de Educação/RJ; Secretaria de Estado de Educação/RJ. Rua Azeredo Lemos, 134, sobrado

24474-110 São Gonçalo RJ - Brasil

marc_araujo_rj@yahoo.com.br
REZNIK, Luís; ARAÚJO, Marcelo da Silva. Imagens constituindo narrativas: fotografia, saúde coletiva e construção da memória na escrita da história local. História, Ciências, SaúdeManguinhos, Rio de Janeiro, v.14, n.3, p.1013-1036, jul.-set. 2007.

Analisa os sentidos que emanam do conjunto de fotografias colecionadas por Luiz Palmier (1893-1955) sobre o Hospital de São Gonçalo, município da região metropolitana do estado do Rio de Janeiro. As imagens constituem uma narrativa sugestiva dos progressos experimentados nessa localidade, especialmente no campo da saúde, constituindo um paradigma para a modernidade nas décadas de 1930 e 1940. Luiz Palmier, médico fundador daquela instituição de saúde, destacou-se como personalidade relevante para a história local e suas ressonâncias em níveis mais ampliados (regional e nacional).

PALAVRAS-CHAVE: Hospital de São Gonçalo; fotografia; memória; saúde coletiva; modernidade; era Vargas.

REZNIK, Luís; ARAÚJO, Marcelo da Silva. Narratives created by images: photography, collective health and the construction of memory in the writing of local history. História, Ciências, Saúde - Manguinhos, Rio de Janeiro, v.14, n.3, p.1013-1036, July-Sept. 2007.

An analysis is made of the meanings that emanate from a set of photographs collected by Luiz Palmier (1893-1955) relating to São Gonçalo Hospital, named after the municipality in Greater Rio de Janeiro. The images comprise a narrative that points to the progress experienced at the hospital, especially in healthcare, which was a paradigm for the modern period in the 1930s and 1940s. Luiz Palmier, who was the doctor and founder of the hospital, was a public figure that played a key role in the local history and its impacts on a regional and national scale.

KEYWORDS: São Gonçalo Hospital; photography; memory; public health; modernity; Vargas era. 
* Este trabalho integra o trabalho de pesquisa do Grupo de Pesquisa História de São Gonçalo: Memória e Identidade, que desenvolveu, entre 2004 e 2006, a pesquisa $\mathrm{O}$ Intelectual e a Cidade: Luiz Palmier e a Conformação de uma São Gonçalo Moderna, e contou com financiamento do CNPq (Edital Universal) e da Faperj (Primeiros Projetos). Uma versão reduzida deste texto foi apresentada no Simpósio da AnpuhRJ, em 2004.

$\mathrm{E}$ ste artigo busca efetuar um breve exercício de interpretação de parcela das imagens da subsérie Hospital São Gonçalo, parte da coleção Luiz Palmier, atualmente custodiada pelo Laboratório de Pesquisa Histórica da Faculdade de Formação de Professores da Universidade do Estado do Rio de Janeiro (Uerj). ${ }^{1}$ Nesses termos, a narrativa sobre a instituição sintetiza importantes relações entre a trajetória de um indivíduo - Luiz Palmier (1893-1955)-, o município de São Gonçalo - que recebe os influxos característicos de uma periferia estabelecida muito próxima geograficamente do centro-, e as políticas públicas da era Vargas no campo da saúde pública que, para além das imposições centralistas, tiveram importante impacto normativo no ambiente intelectual e político.

O Hospital de São Gonçalo foi inaugurado em 1934. Quatro anos depois, uma nova ala, abrangendo novos serviços, foi aberta ao público, dando ensejo a novas comemorações. Na época, em agosto de 1938, os principais jornais de Niterói (O Estado, Diário da

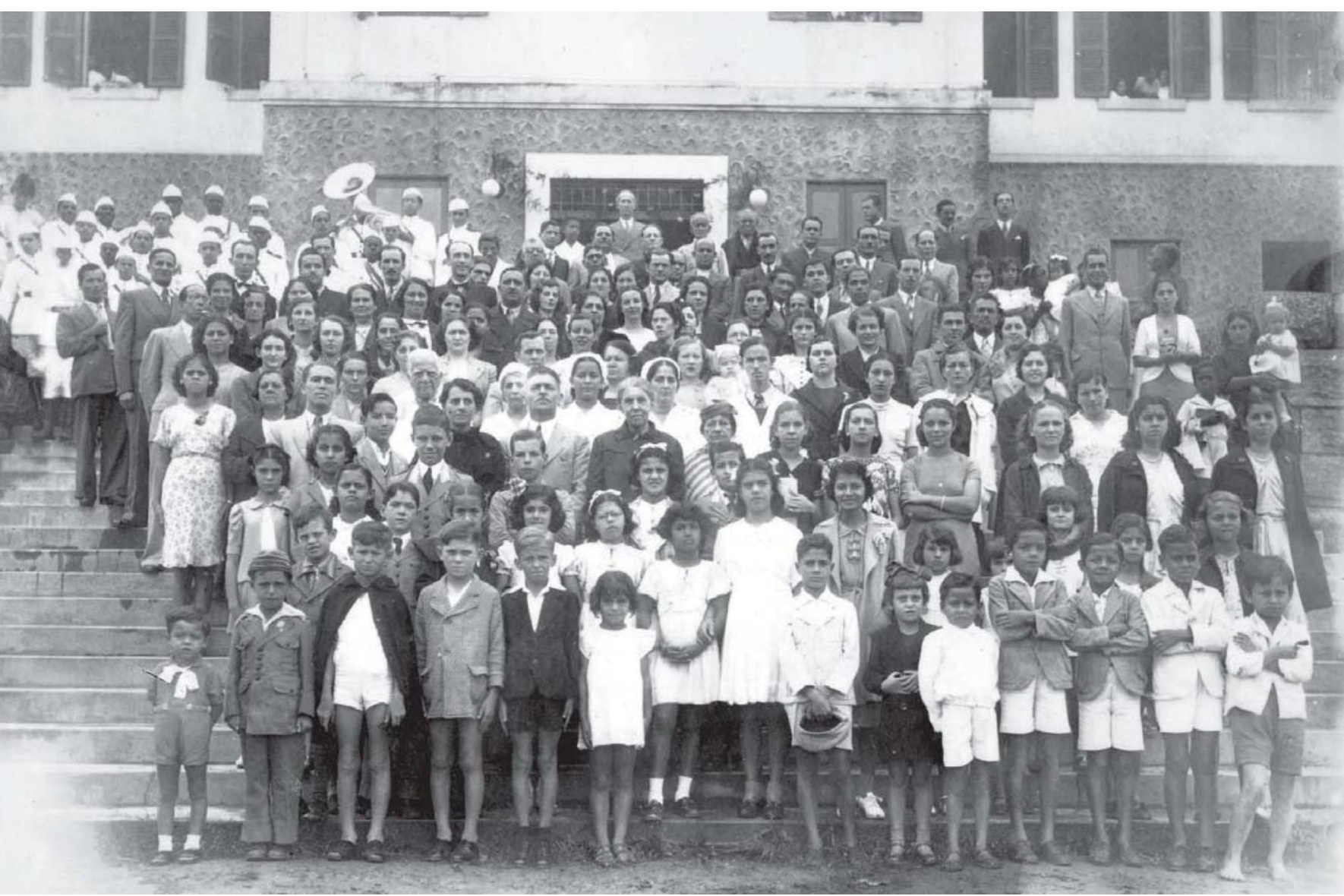

Figura I - Legenda original: "Na escadaria do Hospital. Grupo de pessoas que tomaram parte nas solenidades da inauguração. Médicos, diretores, conselheiros, damas de caridade, associados e funcionários do Hospital”. O Estado, Niterói, 23 ago. 1938. ${ }^{2}$ 
Manhã, O Fluminense) e de São Gonçalo (O São Gonçalo, A Sentinela, O Gonçalense), bem como o Diário Carioca, da cidade do Rio de Janeiro, registraram o acontecimento. Informaram a seus leitores que havia sido inaugurada a ala Jonkopings de Carvalho, em homenagem a um benemérito das obras do Hospital. ${ }^{3}$ Integravam essa ala, medindo pouco mais de cem metros quadrados, novos quartos, a enfermaria para operados, o laboratório, o isolamento e o necrotério. Naquele dia, também foram inaugurados a lavanderia e a sala de médicos.

Discursaram na cerimônia dona Albertina Campos, presidente da Associação do Hospital, os médicos Luiz Palmier e Lauro Batista e os jornalistas Vieira de Macedo e Belarmino Mattos, todos figuras ilustres da cidade. À noite, nos salões da Prefeitura, a festa continuou com um baile ("ao som do jazz do Patronato"4) e a sessão solene para instalação do Centro Médico do Hospital. O Centro era uma sociedade cultural que reunia médicos, farmacêuticos, cirurgiões dentistas e acadêmicos com exercício nos diversos serviços do Hospital. Segundo reportagem de O Estado (23 ago. 1938): “O Hospital de São Gonçalo não é somente uma Casa de Caridade nos moldes das antigas instituições filantrópicas. Trata-se antes de uma moderna instituição de assistência nos moldes de um verdadeiro Hospital-Escola. Os seus modelares serviços, agora muito ampliados, correspondem ao aperfeiçoamento máximo da moderna técnica hospitalar".

Todos os órgãos de imprensa ressaltaram que, durante a cerimônia, foi também 'inaugurado' o retrato do presidente Getúlio Vargas, no salão nobre do Hospital. Sublinhou-se, também, que a diretoria do Hospital recebera um telegrama da Presidência da República, saudando e agradecendo a colocação do retrato.

Tudo isso foi relatado pela imprensa escrita. Quando olhamos para a única foto que acompanhou todos esses registros nos vários periódicos (Figura 1), temos a sensação de que ainda havia muito a dizer sobre o episódio. São elementos com os quais os jornalistas da época não se preocuparam; conseqüentemente, não foram relatados nem detalhados. Como mediadores, ao levar o acontecimento ao grande público leitor gonçalense, carioca e fluminense, fixaram-se no que ele tinha de extraordinário, de novo, ainda que não necessariamente inusitado, pois incorporaram positivamente o evento às suas expectativas. A inauguração da nova ala era a demonstração do progresso e da modernidade. Novidades esperadas e bem-vindas. Aos seus olhos, 'deram conta do recado'. Aos nossos olhos, quanta coisa não foi dita e descrita! Possivelmente são elementos banais para os que ali estavam, facetas de seu próprio mundo, de seu ambiente cultural. Vistos a distância, surge um pequeno fosso, surgem sintomas de um estranhamento. A fotografia revela um mundo não descrito em letras. Assim, abre pis- 
tas para uma outra inserção naquele acontecimento; abre veredas para uma nova narrativa.

Na primeira fileira estão as crianças, meninos e meninas bem vestidos e penteados. Elas com vestidos brancos e laços nos cabelos; eles, de short e paletó. À exceção de um, todos estão calçados (qual será a intimidade deles com os sapatos?). Apenas uma usa óculos, grossos, 'fundo de garrafa'. Crianças loiras e morenas, brancas, negras e mestiças. Estão sérias, de olhos atentos ao fotógrafo, imitando os adultos.

Logo acima, na escadaria, as mulheres. Entre elas, várias 'damas da caridade', senhoras responsáveis pela promoção de festas e eventos beneficentes destinados a coletar recursos financeiros a serem revertidos para a instituição. Ao centro, de chapéu, dona Albertina Campos, presidente da Associação do Hospital de São Gonçalo, agremiação que possibilitou sua construção, administração e permanente manutenção - dona Albertina era reconhecida professora atuante no município, o que denota um movimento, não restrito à localidade, de associação entre educação e higienismo, educação e saúde pública. Entre moças e senhoras, duas se destacam, bem à direita, carregando no colo seus filhos de tenra idade. No centro, as enfermeiras, profissionais da instituição, devidamente caracterizadas, em especial porque é dia de festa.

Entre as mulheres, um homem: Luiz Palmier, ao lado de sua esposa, Olga Palmier. Personagem principal desse evento, Palmier era o diretor do Hospital. Havia sido o idealizador dessa empreitada ao fundar, em janeiro de 1920, juntamente com outras personalidades da cidade, a Associação do Hospital de São Gonçalo. Na época com 26 anos, escreveu sobre a São Gonçalo dos seus sonhos. Entre tantas utopias a se realizar no município, lá estavam o Hospital e seus pavilhões:

Uma só casa de caridade não comportará todo o desenvolvimento, e outros hospitais serão fundados ou, conservada a unidade, o hospital de São Gonçalo terá muitos outros pavilhões em que o amparo às mães será iniciado na maternidade para, em seguida, começar o amparo às crianças nas creches e gotas de leite (asilo de proteção à infância) e mais tarde a proteção ao velho (no asilo de velhice), sem esquecer os pavilhões para tuberculosos e outras doenças de isolamento compulsório. (Palmier, 5 out. 1920)

Utopia nos anos 20, realização nos anos $30 .{ }^{5}$ A disposição dos personagens na fotografia acompanha as preocupações de Palmier no seu texto de 1920: as mães e as crianças deveriam ser amparadas primeiramente. ${ }^{6} \mathrm{O}$ amparo à maternidade e à infância foram elementos primordiais das políticas de saúde pública nos anos 30. As realizações de Palmier estavam sintonizadas com as preocupações dos higienistas de sua época. O Ministério da Educação e da Saúde 
Pública vinha, desde o início da década, fazendo gestões para cuidados especiais nessa direção, entre conferências e agências próprias. ${ }^{7}$ O Instituto Gonçalense de Amparo à Maternidade e à Infância (Igami), fundado em 1939, vem reforçar os empreendimentos nessa direção (Reznik, 2003, p.21-22).

Voltemos à foto. Acima dos homens, todos de terno, à esquerda, uma banda de música! Elemento indispensável em qualquer solenidade oficial da época, a Banda de Música do Patronato de Menores esteve presente em várias ocasiões festivas registradas pelas fotografias da Coleção Luiz Palmier.

Ao fundo, imponente, o próprio Hospital, imensas janelas abertas, pano de fundo da fotografia, objeto principal do evento. As escadarias, como teremos chance de detalhar adiante, foram palco de diversos registros, não apenas de festividades, mas também por ocasião das inúmeras visitas. Construído no centro do distrito sede do município, o prédio, grandioso fisicamente, denotava a sua relevância simbólica. Foi muito enaltecido nas narrativas da imprensa, transformando-se em espaço de visita obrigatória para qualquer um que passasse pela região.

O Hospital foi projetado em 1920 e as obras iniciaram-se com o desbravamento, a terraplanagem e a elevação dos primeiros muros. No decorrer da década, no entanto, ficaram paradas, sendo retomadas em 1931, com o início de ampla mobilização na sociedade gonçalense. Nesses mais de dez anos, plantas diferentes foram desenhadas para o monumento. Após um longo período de campanhas e obras, o Hospital foi inaugurado em 1934, com a presença do interventor federal no estado do Rio de Janeiro, almirante Ary Parreiras, e do prefeito Miguelote Vianna.

Como símbolo do município e expressão das realizações no campo da saúde pública, o Hospital esteve colado à imagem do seu idealizador e primeiro diretor. Não se pode pensar na instituição sem fazer referência a Luiz Palmier e vice-versa. ${ }^{8}$ Por isso mesmo sobressaem, do conjunto de registros fotográficos deixados por Luiz Palmier, aqueles relativos à instituição.

Este texto está dividido em quatro partes. Na primeira discutimos os usos da fotografia como material documental para a pesquisa histórica; em seguida, apresentamos as características gerais da coleção Luiz Palmier; depois, ensaiamos uma pequena biografia de nosso ator principal; e, por fim, desenvolvemos uma análise propriamente dita da subsérie, objetivando refletir sobre as questões que envolveram a construção e manutenção daquele que é o centro pioneiro das políticas e práticas de uma certa concepção de modernidade local e regional. 


\section{A fotografia e os seus usos}

Foi na primeira metade do século XX que a utilização da máquina fotográfica tornou-se popular. Para além da crescente e veloz evolução tecnológica que a envolveu, a fotografia passou a figurar como um discurso da verdade, importante documento comprobatório de um acontecimento. Não foram poucos os dirigentes políticos que lançaram mão de sua utilização. Para muitos historiadores da fotografia, localiza-se entre as duas grandes guerras, mais do que qualquer outra época, o momento em que a imagem passou a ser explorada em todas as suas potencialidades. A fotografia dos anos 20 caracteriza-se pelo aparecimento de uma grande variedade de estilos, técnicas e aproximações com outras artes visuais. Uma nova perspectiva abriu-se no domínio da expressão fotográfica, valorizada tanto pela sua objetividade, como elemento de prova, quanto pelas possibilidades de experimentação, como composição artística e estética (Lacerda, 1994).

Outras funções desempenhadas pela fotografia tiveram seu auge nesse período. A partir da metade da década de 1920, ela começa a ser utilizada sistematicamente pela imprensa escrita. ${ }^{9}$ Visando objetivos promocionais - institucionais, comerciais, políticos e turísticos -, alcançou grande canal de expansão através dos diversos veículos de comunicação: nas publicações oficiais, nos cartõespostais e nas revistas ilustradas. Vale lembrar que a fotografia passou a figurar nos vários documentos de controle e identificação da sociedade de massas do século XX: título de eleitor, passaporte, certificado de reservista, carteira de identidade e carteiras de agremiações, entre outros (Kossoy, 1993; Mauad, 2004).

Passou-se, cada vez mais, a conferir à fotografia um caráter de testemunho verídico dos acontecimentos. Renata Silva (1998, p.67) nos traz um bom exemplo dos primórdios do século XX:

O cunho de registro documental era muito explorado. Um exemplo desta função era a utilização das fotografias de Malta pelo pessoal da prefeitura encarregado da avaliação dos imóveis a serem desapropriados. Os proprietários insatisfeitos com os valores oferecidos a seus imóveis geralmente marcavam uma audiência com o prefeito para discutir os preços. Para o encontro, Passos trazia fotografias do imóvel deixando surpresos seus proprietários. Nunca antes as fotografias foram usadas com esta finalidade, era inédito.

Do ponto de vista dos usos da fotografia no campo da pesquisa histórica, a década de 1980 é tida como marco inicial, no Brasil, do reconhecimento do estatuto acadêmico da fotografia como documento. Ela é indubitavelmente portadora de um grande potencial para os estudos históricos, já que pode, por meios diversos dos usualmente tratados pelos pesquisadores, comunicar uma atmosfera e exprimir sentimentos. 
É extensa, conhecida e de qualidade a bibliografia que trata do aparecimento da fotografia e de suas utilizações para as mais diversas finalidades. Entre alguns autores que refletem sobre ela, podemos citar, no cenário internacional, nomes como o de Roland Barthes (1984, 2000), Philippe Dubois (1992) e Walter Benjamin $(1994,2000)$ e, no plano nacional, autores como Ana Maria Mauad (1996, 2000), Antônio Oliveira Junior (2000) e Boris Kossoy (1989, 1993), entre muitos outros.

Em contraposição a um discurso positivo que compreende a fotografia como espelho da realidade, ou como reapresentação da verdade dos acontecimentos, esses pesquisadores argumentam que a fotografia apresenta um fragmento selecionado da aparência das coisas, das pessoas, dos fatos, tal como foram esteticamente congelados num dado momento de sua existência/ocorrência. Em outros termos, a fotografia não comporta a verdade plena de um acontecimento social, mesmo sendo produzida com esse objetivo. Assim como as demais fontes de informação histórica, a fotografia é um 'artefato social' que deve ser interpelado a partir de um processo de interação entre o produtor da imagem, seu objeto e nós, seus espectadores. O fotógrafo, tal qual o historiador, 'conecta o real' e o representa através do foco de sua câmera. A seguir, para persuadir seu público da verdade contida na sua representação, nos apresenta a imagem, a fotografia em papel. Dessa forma, ela é o final de um processo metódico cuja finalidade é narrar eventos. ${ }^{10}$

Como afirma Kossoy (1993, p.14), "assim como os demais documentos, elas são plenas de ambigüidades, portadoras de significados não explícitos e de omissões pensadas, calculadas, que aguardam pela competente decifração". Ao analisar uma fotografia, devemos ter o cuidado metodológico de não esquecer que o interesse por certas questões é determinado pela época e pelo grupo ao qual pertencemos. A história que construímos é, portanto, uma história do nosso tempo, cujos temas são escolhidos entre aqueles mais caros em termos políticos, sociais e culturais. A interpretação requer, portanto, o conhecimento da cultura ou aspecto estudado, pois só assim será possível chegar à compreensão do todo com base no fenômeno individual observável: "A leitura da fotografia é, pois, sempre histórica: depende sempre do saber do leitor ..." (Barthes, 1984, p.21; grifo nosso).

Em outras palavras, é isso que nos ensina o genial fotógrafo Sebastião Salgado (citado em Morais, 1998, p.136):

Existe uma corrente que diz que a fotografia é objetiva, representa uma realidade, nem mais nem menos. Ela é imparcial e mostra a realidade total ... Não é verdade! Isto é a maior mentira do mundo. Você não fotografa com a sua máquina. É a coisa mais subjetiva que existe. Você fotografa com toda a sua cultura, com 
os condicionamentos ideológicos. Você aumenta, diminui, deforma, deixa de mostrar. A fotografia é uma maneira de viver, de continuar o trabalho social e ideológico.

\section{A coleção Luiz Palmier}

A doação, feita ao Grupo de Pesquisa História de São Gonçalo, de um grande número de fotografias originais, acumuladas em vida por Luiz Palmier, deu novos rumos à pesquisa biográfica - como veremos adiante - sobre essa figura reconhecida pela sua imersão na vida pública do município de São Gonçalo entre 1920 e 1955. As imagens retratam uma faceta do itinerário de Luiz Palmier, cujos registros apontam as escolhas, os posicionamentos e a conseqüente materialização de suas intenções.

São aproximadamente setecentos registros, todos em películas em preto e branco, de diversos formatos e tamanhos, com predileção pela dimensão $18 \mathrm{~cm} \times 24 \mathrm{~cm}$. Cobrem várias temáticas e épocas da vida pessoal e profissional, revelando elementos para a decifração de sua atuação na política, no mundo acadêmico, nos estudos de folclore fluminense e nas áreas de saúde e educação, facetas privilegiadas na obra que fez de sua existência. Em sua maioria, as fotografias estão em ótimo estado de conservação, permitindo uma apropriada leitura e análise.

Trabalhando com o suporte fotográfico percebemos que cada registro discursa por si, pois porta uma expressão única, individual. Contudo, é o seu conjunto que expressa uma relação com o sujeito que o gerou. Com base nessa premissa, notamos que as imagens fotográficas da coleção Luiz Palmier contam uma história. Constituem uma narrativa acerca de um período histórico e de uma postura perante políticas públicas, especialmente na área da saúde. Como resultado, as imagens constroem uma memória, imprimindo uma determinada interpretação e condução histórica. Nesse sentido, é lícito afirmar que as coleções fotográficas - sejam essas que focam a vida pública, sejam aquelas que fazem parte dos álbuns de família -, assim como outros discursos que interpretam e 'editam' as experiências do passado, podem ser usadas para elaborar um mundo substituto, regulado por imagens que exaltam, consolam ou atormentam.

Na coleção Luiz Palmier, as fotografias inscrevem-se como documentos monumentalizados, escolhidos para representar os contextos vivenciados (Le Goff, 1984). São peças singulares, relacionadas entre si, que objetivam perenizar um foco sobre os acontecimentos, uma memória, uma narrativa, uma interpretação dos eventos públicos retratados. Configuram, pois, uma educação do olhar, informando aos partilhadores da mesma cultura e, portanto, potenciais leitores, um dado sentido. 
Na definição de Krzysztof Pomian (1984, p.53), uma coleção é um conjunto qualquer de objetos mantidos temporária ou definitivamente fora do circuito das atividades econômicas. Além disso, ela deve estar sujeita a uma proteção especial, em local fechado e preparado para esse fim, e exposta ao olhar do público. O que de fato importa em uma coleção não é necessariamente o número de objetos que lhe dão corpo, mas sim suas funções, que lhe permitem exprimir-se em seus caracteres observáveis. Em geral, esse número de objetos depende do local em que se acumulam, do estado da sociedade, suas técnicas e modo de vida, da importância que se atribui à comunicação entre o visível e o invisível por intermédio dos objetos, entre outras coisas.

Esses conjuntos não são mais do que manifestações dos locais sociais em que se operam, em graus variáveis e hierarquizados. Em outros termos, a transformação do invisível no visível é o elo entre dois mundos: o nosso propriamente dito e aquele construído pela representação dos objetos em exposição. A mediação entre ambos é o que as coleções efetuam, dando-lhes os mais diversos significados. Não raro, como nas fotografias em apreço, essa mediação manifesta, por meio de seu simbolismo, uma hierarquia social, ao dotar de superioridade determinadas insígnias reconhecidas socialmente, realizando assim um exercício de dominação nesse meio.

Pode-se portanto concluir que uma reflexão sobre as coleções (e sobre os colecionadores) não se fecha no quadro conceitual de uma psicologia individual que provê todas as explicações tendo por referência noções que, nesse caso, são simplistas, tais como o 'gosto', o 'interesse', ou ainda o 'prazer estético'. O desenrolar do arquivamento e da constituição de uma coleção (fotográfica) deve-se à própria documentação do social, da criação e da implementação de uma política de relevante abrangência.

$\mathrm{O}$ ato de fotografar, para Palmier, ou melhor, o ato de acumular fotografias, pois ele não era o fotógrafo, cumpria, podemos supor, três objetivos: noticiar, divulgar e monumentalizar para a posteridade. Noticiar significa informar, reapresentar a cena ou o episódio em outro lugar, de forma que um número maior e mais variado de pessoas possa ter 'acesso' àquele evento. Em várias ocasiões, as fotos foram usadas imediatamente pela imprensa escrita. Em outras, compuseram material para congressos e jornadas científicas.

O segundo objetivo foi a divulgação, apresentando um caráter de propaganda. Sem dúvida, o conjunto de registros que foram utilizados no livro São Gonçalo - cinqüentenário (Palmier, 1940) tiveram a intenção de enaltecer certos aspectos da vida na localidade.

Por fim, podemos supor que os registros simplesmente cumpriam a função intencional de imortalização dos acontecimentos. Nesse sentido, Palmier quis acumular um conjunto que documentasse e ao mesmo tempo monumentalizasse a sua 'obra' (Le Goff, 1984). 
Essa documentação foi guardada com zelo pela família, na medida mesma em que comprovava o legado do seu familiar como que por imagens, na sensação tão cara a todos nós do forte sentido afetivo que carregam as imagens familiares, os álbuns de família.

O conjunto das fotografias expressa a atuação pública de Luiz Palmier. No entanto, não sabemos se ele se preocupou, em vida, com uma ordenação racional. Não restaram vestígios de um arranjo pessoal. Embora contendo anotações no verso e, algumas vezes, na face emulsionada, elas apresentavam incongruências, rasuras, riscos e, por vezes, comentários algo indecifráveis. Não parecia haver propósito de exibi-las publicamente.

Nesse sentido, o conjunto imagético acumulado por Luiz Palmier não perfazia uma coleção, tal como definimos há pouco. Foram os pesquisadores que trataram técnica e metodologicamente os registros, conformando um determinado arranjo sob a pretensão de dotar o conjunto de uma organicidade e, por assim dizer, formar uma coleção - um conjunto de objetos separados, protegidos e expostos ao público. Portanto, a noção de coleção encampa, nesse caso, de modo externo e a posteriori, os documentos. Isso se fez necessário para a reconstrução do percurso da 'realidade' materializada pelas fotografias em suas relações com o tempo e os temas que compreenderam. Assim, foi o exercício de historiar o fragmentado e o parcial, aspectos inescapáveis do ofício do historiador, que, ao evitar a possibilidade do anacronismo, concedeu a esses fatos imagéticos a qualidade de composição de um cenário narrativo de uma época e suas especificidades.

A coleção Luiz Palmier, considerada como um fundo arquivístico, foi organizada em séries que pretendem retratar as diversas facetas da vida desse personagem: Família, Político, Saúde, Educação, Igami, Homem de letras, Eventos e Produção Intelectual. Para fins deste artigo, iremos trabalhar com a subsérie Hospital de São Gonçalo, identificada pela notação arquivística CLP_SA_HSG, que significa: coleção Luiz Palmier; série Saúde; subsérie Hospital de São Gonçalo. Encontram-se aí 73 fotografias, produzidas entre 1931 e 1942, representando desde as plantas arquitetônicas até as variadas solenidades que tiveram lugar no Hospital. Desse número, apenas consta a identificação do fotógrafo ou do estúdio em 21 fotografias. Identificamos: Everardo T.M. Bacellar (Photo S. Gonçalo), 14 fotografias; Manuel Fonseca, cinco fotografias; e A. Roldão e Photo S. Paulo, uma fotografia cada um.

O conjunto dessa série perfaz uma trajetória que contempla diferentes aspectos dos espaços representados, tais como festividades, visitas, inaugurações e construções, todos apresentando os elementos (humanos e físicos) que as imagens sugerem ser os mais importantes da trajetória da instituição. Entender que essas características estão vinculadas a um tempo e a um espaço distintos leva- 
nos a privilegiar um olhar imerso numa outra historicidade, conferindo especial relevância aos detalhes, tais como a indumentária, as posturas corporais, os trejeitos e a composição cênica.

\section{Pequena biografia de Luiz Palmier}

Chegando ao município de São Gonçalo em 1918, Luiz Palmier cedo tornou-se figura marcante na promoção e nos cuidados à saúde da população local, imprimindo-lhes novos rumos e direções. Apresentaremos aqui uma pequena biografia de nosso protagonista, percorrendo sua trajetória de vida a fim de reconstruir a série de sociabilidades e relações que possibilitam vislumbrar a vida pessoal do médico e as transformações locais dessa época.

Nascido em Sapucaia, interior do estado do Rio de Janeiro, em 21 de setembro 1893, Luiz Palmier era o terceiro filho de uma prole de seis. Sua família dedicava-se à lavoura e invariavelmente passava por dificuldades financeiras. Tendo sido balconista de uma farmácia na juventude, Palmier iniciou-se aí nos segredos da área, conciliando com esforço o trabalho e os estudos até que, em 1912, formou-se na Escola de Farmácia de Ouro Preto, em Minas Gerais, primeira na América Latina e hoje uma unidade da Universidade Federal de Ouro Preto (Ufop).

Em 1918 Palmier iniciou o curso de medicina pela Faculdade de Medicina do Rio de Janeiro - atualmente um dos centros da Universidade Federal Fluminense (UFF) -, mesmo ano em que passou a colaborar no tratamento e combate à epidemia da gripe espanhola. Não concluiu o curso de medicina no prazo previsto, tendo-o feito apenas em 1932, quando conseguiu retomar os estudos após seu casamento (1925) e a chegada dos filhos.

São Gonçalo, no início do século XX, passava por grandes transformações sociais e políticas, na busca por municipalização. A partir de finais da década de 1910, o poder instituído local passa a intervir minimamente para ordenar o espaço público no campo urbanístico e de serviços. Durante esse processo, Luiz Palmier destacou-se nas áreas de saúde e educação, dimensões estratégicas para a construção da identidade e das políticas públicas de desenvolvimento da cidade, obtendo projeção profissional logo após sua chegada e passando a manter laços e a conviver com a elite local.

Mostrou-se imediatamente um crítico da falta de cuidados com a higiene - privada e pública - da comunidade local e entrou em embate com os detentores dos saberes práticos da medicina popular, os curandeiros. Saneamento básico e cuidados com a saúde eram questões primeiras de sua defesa: o município não possuía nenhum hospital, sendo a saúde coletiva assistida por um posto de saúde que não dava conta do volume de demandas. 
Fazia-se necessária a criação de uma entidade que viabilizasse a concretização desses ideais. Assim, a partir de sua mobilização bem como dos cidadãos ilustres do município, depois avolumada também por populares dos mais diversos estratos sociais, foi marcada para $1^{\circ}$ de janeiro de 1920 uma reunião aberta no Grêmio Artístico e Literário da cidade, a fim de organizar uma comissão com essa finalidade. O convite público obteve sucesso: o auditório estava repleto. Após as discussões, estava criada a Associação do Hospital de São Gonçalo, que passou a funcionar num prédio doado pela Prefeitura, no centro da cidade, e cuja presidência foi conferida a Palmier.

Longa jornada até a concretização do Hospital, em 1934. Paralelamente, Luiz Palmier preocupava-se com a educação, problemática da qual fazia sua segunda pele, destacando-se como ícone de várias causas e realizações nesse campo. Em maio de 1942, recebe da vida um duro golpe: seu primogênito, carinhosamente alcunhado de Luizinho, foi vítima fatal de um grave acidente em casa, o que ocasionou grande comoção e prostração à família, especialmente a Palmier, que via nele seu sucessor profissional. Tal fato parece desnortear decisivamente o precursor dos cuidados médicos sistematizados de São Gonçalo, fazendo-o, por essa época, afastar-se progressivamente das questões de caráter mais administrativo do Hospital, postura que mantém até sua morte, em 16 de outubro de 1955.

Em síntese, como demonstração da produção bem como da preocupação de Luiz Palmier com São Gonçalo, há que se atentar para sua principal obra como escritor, São Gonçalo cinqüentenário: história, geografia, publicada em 1940 em comemoração aos cinqüenta anos de emancipação política e administrativa do município. Nela, o autor trata de vários temas, procurando dar conta do desenvolvimento da cidade e de seu potencial no conjunto dos municípios do estado.

Luiz Palmier foi médico, farmacêutico, educador, escritor, político, jornalista, geógrafo e historiador, entre outras atuações, tendo desempenhado um sem-número de funções públicas e profissionais. Mesclou sua imagem à do município, assentando neste uma marca reconhecida de desenvolvimento social, econômico e político.

Na próxima parte, abordamos mais detida e analiticamente alguns itens fotográficos, entre registros de ambiente interno e externo do Hospital de São Gonçalo, que elegemos em virtude de sua exemplaridade na retratação dos principais aspectos cotejados em nossa discussão.

Dado o volume de registros da subsérie, elaboramos eixos temáticos de classificação: Construção (12 imagens), Vistas (sete imagens), Inaugurações e Posses (33 imagens), Mantenedores e Funcionários (quatro imagens), Visitas (13 imagens) e Serviços Hospitalares (quatro imagens). Em Construção, incluímos as plantas 
Seguindo-se a uma intensa campanha que envolveu esforços variados, tais como doações mensais de sacos de cimento por parte de empresas e indivíduos, e a organização de encontros beneficentes como festivais, 'chá dançante' e 'sorvete dançante', as obras do Hospital, após um longo intervalo, foram reiniciadas em 1931. As fases de sua construção estão fartamente documentadas nas fotografias, eternizando suas diversas etapas.

É curioso notar como se trabalha a imagem, de modo a deixar entrever, se comparada com outros registros existentes na coleção, a evolução da localidade. Como a dizer "o progresso chegou!", a fotografia apresenta um derredor descampado e potencialmente árido, e a construção surge como bastião de certa proposta civilizatória, que se constrói gradativamente na cidade. Como sugeria, a propósito, um trecho publicado no Jornal de Nictheroy (30 dez. 1933): “O Hospital de S. Gonçalo será, sem dúvida, o marco iniciador de uma nova fase de progresso pela qual o vizinho irá reabilitar-se do marasmo em que tem vivido e do desbaratamento de suas finanças, de suas energias vivas tão mal orientadas em administrações que se foram".

Após intervenções e pioneirismo da sua elite intelectual e empreendedora, o município passou a contar com uma instituição de saúde. Nos anos que se seguiram, o entorno apresentado pela fotografia seria transformado e passaria a representar a face 'correta' de uma cidade que aspira ao desenvolvimento merecido. À nova face dessa urbanização contrapõem-se os detalhes da natureza, seja da paisagem montanhosa que emoldura a cidade, seja dos recantos bucólicos de seus arredores.

Outra característica que chama a atenção na edificação é o aspecto explícito de monumentalidade. Este lhe confere uma imponência que a singulariza não somente quanto às demais existentes no município, mas também quanto ao seu percurso socioeconômico. Poderíamos nos arriscar a afirmar que a paisagem urbana, assim fixada, configura-se como o registro de um momento determinado da produção espacial, em que se estabelecem novas relações entre cidade e natureza. Concordamos com Alvarez (1991, p.17) quando defende que, através do instrumento arquitetônico, normalmente é possível reificar a paisagem e permitir que ela, em seu impacto visual, galgue um patamar do imaginário coletivo.

Nesse sentido, a forma de captação da imagem tem especial importância. O ângulo usado, levemente de baixo para cima, também auxilia na condução do olhar do leitor/espectador. A constatação da pequenez dos elementos humanos hiperdimensiona o prédio: sem dúvida, esse caráter monumental é conferido à centralidade da construção que 'puxa' o olhar para seus contornos e medidas.

A arquitetura de formas geométricas promove grande impacto visual. Assegura, até mesmo para os leigos, a impressão de um 
projeto moderno, na medida das aspirações de um município que se pretendia fadado ao progresso. Se pensarmos nas afinidades entre as propostas locais e as políticas varguistas na área de saúde, é lícito argumentar que a construção e o funcionamento do Hospital, em meio a um cenário adverso, evocam fortemente as propostas normativas do Estado na área da saúde. Assim, a fotografia adjetiva um discurso que se materializa numa arquitetura de determinado padrão de civilização.

\section{Vistas}

Segundo Lacerda (1994), as reformas urbanas ocorridas no início do século XX no Rio de Janeiro, com vistas à construção da avenida Central, produziram um cenário cuja dinâmica de transformação justificava a produção de uma documentação fotográfica

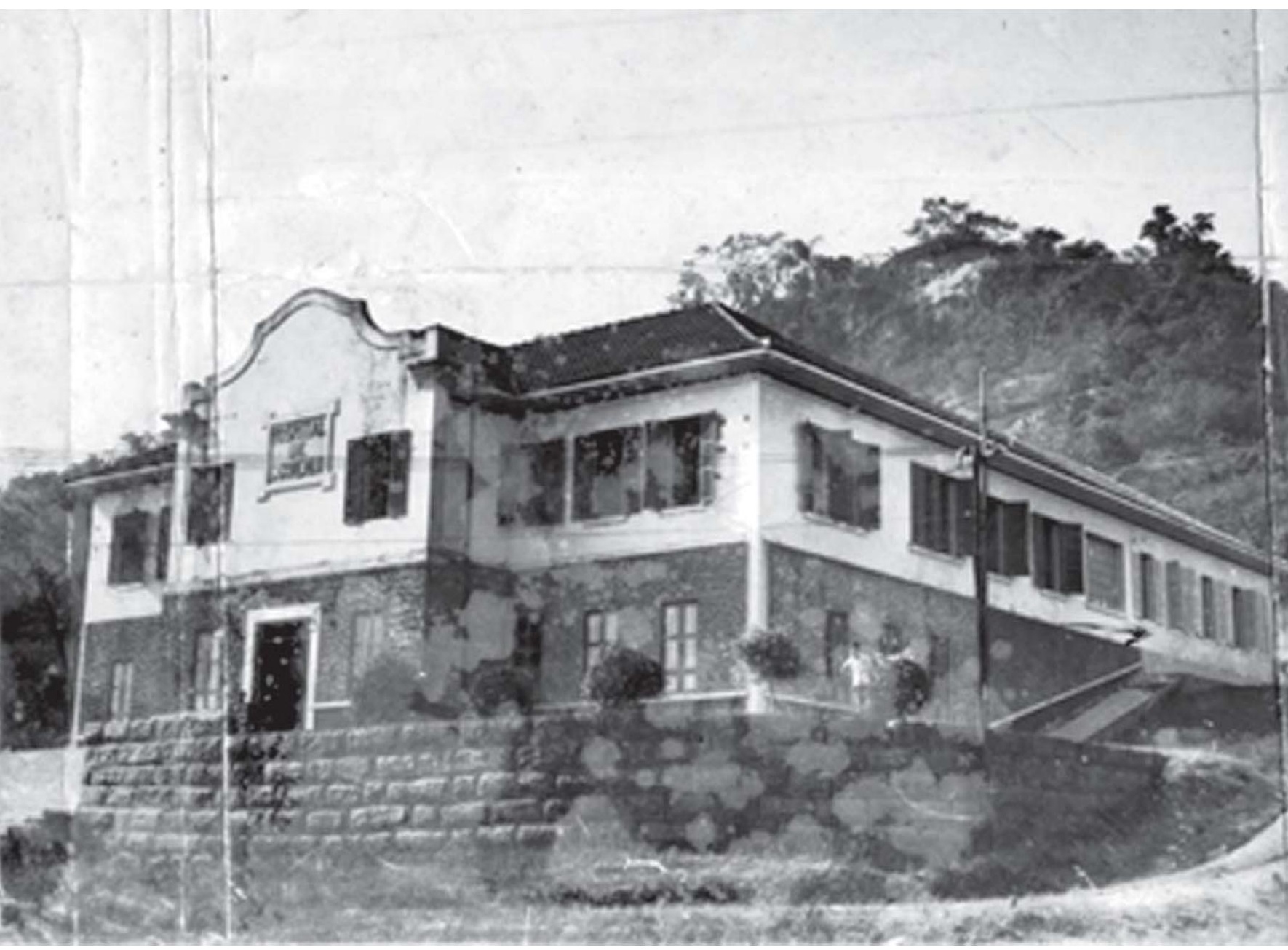

Figura 3 - Coleção Luiz Palmier, série Saúde, subsérie Hospital de São Gonçalo. Sem autoria; 1938 
que registrasse as mudanças. Marc Ferrez encarregou-se dessa tarefa. A mesma motivação, guardadas as proporções e especificidades do município em questão, animava Luiz Palmier.

A fotografia, como instrumento de divulgação de idéias, apresentava um projeto de cidade que antecipava sua verdadeira construção. O documento iconográfico pretendia ser o registro da fundação de um (novo) tempo, posto em marcha pela detonação de 'políticas' de estabelecimento de memória, a qual tende a ser dinâmica, moderna e criadora.

Materializado no projeto e na construção efetiva do prédio, o Hospital aparece imponente na Figura 3. O registro enfatiza a verticalidade. De acordo com alguns estudiosos da arquitetura, quando na composição monumental adota-se o vertical como dominante numa base horizontal, a escala amplia as formas, a disposição volumétrica lhe serve de moldura (Alvarez, 1991, p.25). Em muitos dos registros externos, como este, denota-se uma imperiosidade, um aspecto grandioso arquitetônica e estruturalmente. $\mathrm{O}$ fotógrafo parece trabalhar com objetivos claros: opera seu instrumento medindo distância, ângulo e posicionamento. Percebe-se a opção por apresentar a imagem do prédio na íntegra. A tomada se dá levemente de baixo para cima e de forma um pouco inclinada, igualmente direcionando a condução do olhar. Certa racionalidade é demonstrada na representação do Hospital: explicita a divisão calculada de suas dependências e a fachada com a parte central protuberando, o que dá a sensação de acolhimento.

Embora a fotografia não esteja em perfeito estado de conservação, pode-se ainda perceber a presença de uma pessoa na parte lateral do Hospital. Mesmo enigmática, é possível supor que ela tenha uma função na representação, ainda que isso não tenha sido objeto de planejamento consciente por parte do fotógrafo. Aqui, mais uma vez, a demonstração de grandiosidade e monumentalização corre ao encontro do olhar do espectador. O elemento humano é diminuto em relação ao Hospital, o que, por outra tradução visual, poderia levar a supor uma plena funcionalidade e eficácia. Tomando mais uma vez de empréstimo as palavras de Lacerda (1994, p.254), a fotografia "amplia as perspectivas, estabelecendo relações e associações de idéias através de uma nova estratégia discursiva, calcada exatamente nesses dispositivos de exibição".

Na comparação entre as Imagens 2 e 3 é possível conferir uma transformação na paisagem do entorno. O Hospital preenche, na última delas, quase todo o espaço da fotografia, dando a impressão de uma região mais urbanizada. Não apenas as rampas de acesso, mas principalmente as instalações elétricas são sintomas dessas mudanças. Os fios de eletricidade, a novidade do século, presença recente no município (Machado, 2002), atravessam tenuemente a fotografia. 
A preocupação com a estética externa da construção é uma constante em toda a série. O Hospital propiciou um esforço urbanístico nas suas cercanias. Vários melhoramentos foram realizados no seu perímetro, apresentando um novo arranjo que tem como base a composição dos prédios, das árvores e do passeio público. Em novembro de 1934, meses após a inauguração, a Prefeitura entregava à população a praça defronte ao prédio, belamente ajardinada. Conforme Palmier, "continuava a melhorar o ambiente urbano da antiga vila, caminhando já para uma completa remodelação" (Palmier, 1940, p.99). ${ }^{11}$

\section{Visitas}

Inúmeras e diversas foram as visitas feitas ao Hospital de São Gonçalo, dando-lhe significado como ponto de referência simbólica na cidade. Personalidades, autoridades e grupos vinham conhecer suas instalações. Foram retratados desde membros do clero católico e batista, passando pelo conde Pereira Carneiro e pelo diretor de Higiene de Goiás, até membros do Moto Club Santa Cruz, uma agremiação de motociclistas.

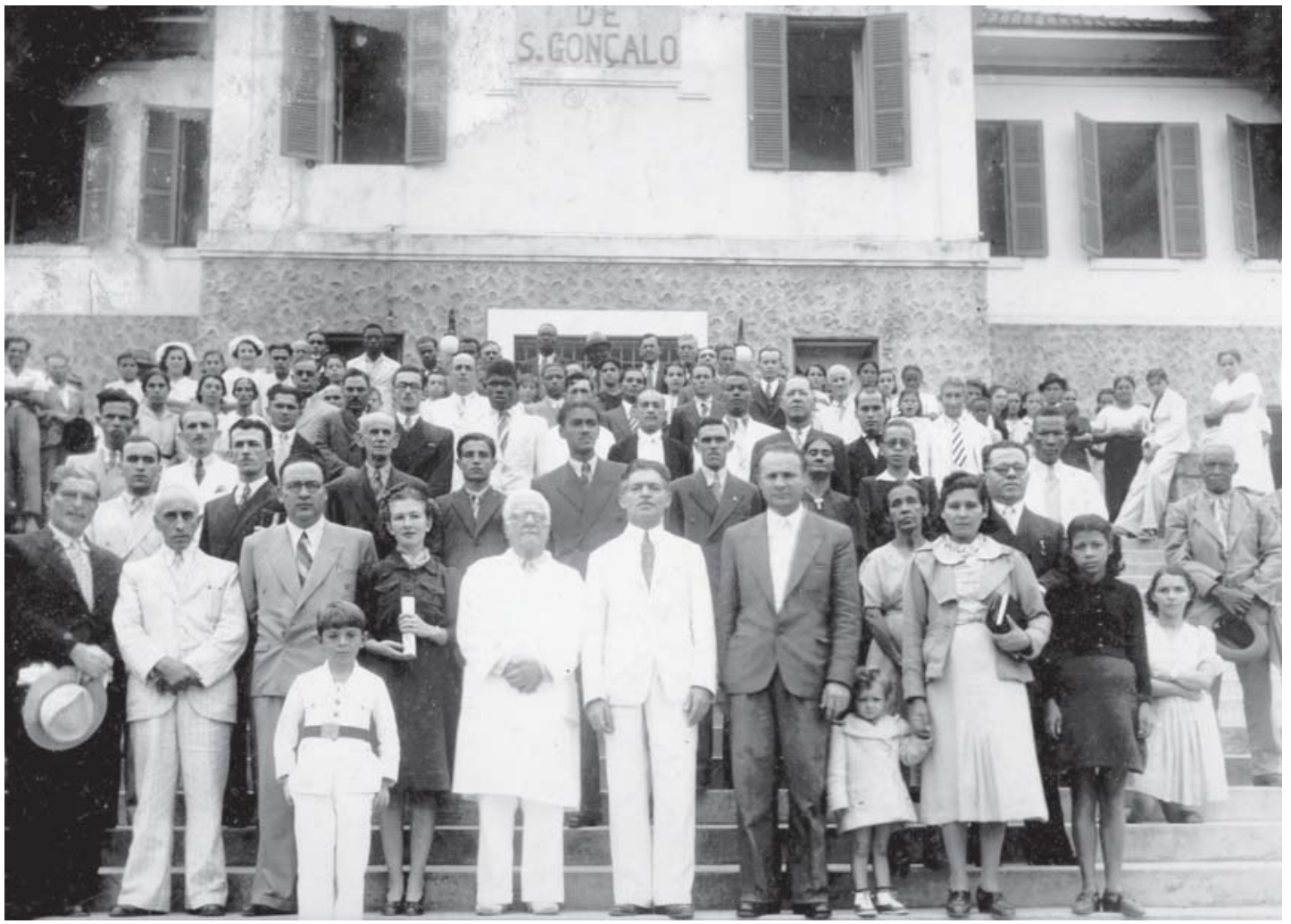

Figura 4 - Legenda original: “A Convenção Batista Gonçalense visitou o Hospital de S. Gonçalo na última 3” feira”, O São Gonçalo, São Gonçalo, 23 jun. 1940. Foto Everardo T.M. Bacellar (Photo S. Gonçalo), jun. 1940 
Durante essas visitas não podia faltar a presença da autoridade executiva municipal, ou melhor, das autoridades, visto que se sucederam as administrações e manteve-se a prática de comparecer às solenidades. Isso evidentemente conferia mais prestígio e consistência simbólica à instituição. No que tange a Palmier, hábil e meticuloso recepcionista, o Hospital foi uma espécie de seu 'cartão' particular para as visitas mais variadas. Da forma como foram produzidas, as imagens chegam mesmo a sugerir uma simbiose entre essas duas figuras, o homem e a instituição, mitificando a ambos. Em associação e para além dessa simbiose, atribuíam-se a Palmier perfis valorizados na época: homem público, cientista, chefe de família, filantropo etc.

A Figura 4 retrata a visita de religiosos batistas. Sob a legenda "Visita dos membros da Conferência Batista ao Hospital de São Gonçalo", temos o registro do fotógrafo Everardo T.M. Bacellar (Photo S. Gonçalo), em junho de 1940. Em periódico da época, noticiou-se que a convenção fora realizada no município, na Igreja Evangélica de São Gonçalo.

Na foto, em primeiro plano, temos, entre outros, o advogado e jornalista Antônio Vieira de Macedo (segundo à esquerda), figura sempre presente em solenidades e acontecimentos sociais. Ao seu lado, o pastor Waldemar Zarro, da Primeira Igreja Batista de São Gonçalo. Palmier é o sexto à esquerda. Veste roupa branca, que sugere uma aproximação com o seu uniforme de trabalho, acrescido de uma gravata, posta possivelmente em virtude da ocasião solene.

A composição das imagens em perspectiva (plano) ascendente foi a solução plástica encontrada para retratar a totalidade dos presentes. $\mathrm{O}$ fotógrafo hierarquiza nitidamente os elementos componentes - à frente, os visitantes e autoridades municipais e da instituição; atrás, os funcionários. Destaca-se, ao centro e à frente, Luiz Palmier, conferindo-lhe distinção. Ao fundo da imagem percebemse vários populares, marca registrada das fotografias da coleção. Esses avalizavam costumeiramente os eventos com a sua presença, o que é essencial para compreender a importância da instituição na vida gonçalense.

Mais uma vez a monumentalidade do prédio extrapola o motivo 'realista' da imagem. Suas janelas abertas compõem um cenário que pode significar o acesso amplo ou livre por parte da população, além das práticas de arejamento ambiental como auxiliadores do restabelecimento da saúde.

\section{Serviços hospitalares}

Por serem raros, na subsérie, os registros de pacientes, consideramos essa imagem uma preciosidade. Trata-se de uma fotografia de refinada elaboração. $\mathrm{O}$ ambiente é interno, no salão principal do 
Hospital, demonstrando que não se quer nenhuma interferência externa ao motivo principal do registro. O cenário é composto para nele figurarem tão-somente a família de pacientes e o médico.

O impaludismo, também conhecido como malária, foi uma das principais preocupações dos higienistas, pelo menos desde o início do século $X X$, em relação às endemias que grassavam no país (Hochman, 1993). Paralelamente aos esforços para impedir sua disseminação, o combate à doença foi tema de teses acadêmicas apresentadas em vários congressos dos quais Palmier participou. Destacam-se as Primeiras Jornadas Médicas Fluminenses, ocorridas em Campos (RJ), em 1935, onde Palmier apresentou o trabalho "A lepra - problema mundial", representando o Hospital de São Gonçalo.

A Figura 5 destaca, portanto, alguns trunfos da 'obra de assistência social' realizada pelo Hospital. Em primeiro lugar, a atenção particular aos pacientes de malária, denotando esforço para operar em sintonia com as preocupações da época. Em segundo, quanto à origem da família, que é de Campos, região norte fluminense que vinha apresentando manifestações de impaludismo. Por último, mas não menos importante, Palmier quis evidenciar o alcance de atuação

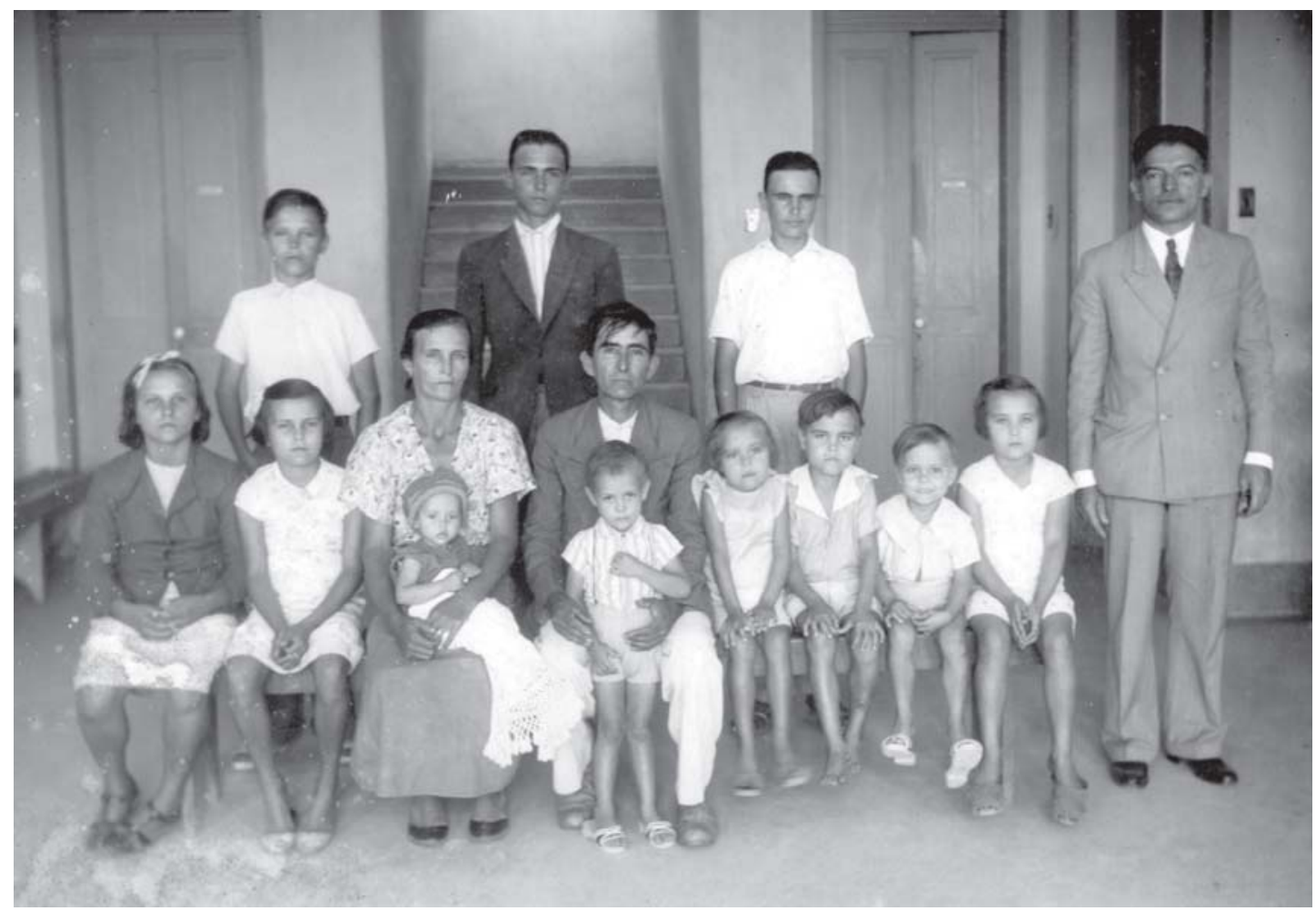

Figura 5 - Legenda original: “Uma família de 13 pessoas, os pais e 11 filhos, todos impaludados, originários de Campos, com passagem por Casemiro de Abreu, todos curados nos ambulatórios do Hospital de S. Gonçalo”. Foto: Everardo T. M. Bacellar (Photo S. Gonçalo), s.d. 
de sua instituição. O Hospital de São Gonçalo, como tantas vezes foi louvado na imprensa local, seria um instrumento de saúde pública para toda a região fluminense. ${ }^{12}$ Representantes médicos do Hospital atuaram na Baixada Fluminense, mais precisamente em Duque de Caxias (Saneamento..., 5 set. 1935).

\section{Mantenedores e funcionários}

A grande maioria das fotos da subsérie é de exposições em ambientes externos, em geral nas escadarias do Hospital ou à frente do Biotério e do Pronto Socorro, os outros prédios que compunham o complexo de saúde. É este o tom predominante do conjunto de fotografias: registrar eventos em que se reúnem grupos de pessoas. Há, no entanto, várias fotos do interior do Hospital, tais como as de cerimônias de posses das diretorias da Associação. Em sua quase totalidade, o cenário é o salão principal, a exemplo da Figura 5.

A Figura 6 traz uma novidade: registra a enfermaria. Um salão limpo, arrumado, com móveis aparentemente novos e bem distribuídos. Ambiente asséptico, claro, denotando uma forte preocupação em transmitir uma idéia de higiene. É uma foto tipicamente 'montada': os móveis à frente, foco no vazio do corredor, a área de passagem que nos leva até as enfermeiras, personificação dos cuidados qualificados da instituição. Essas profissionais funcionam como coadjuvantes, compondo o cenário - não é à toa que se encontram em plano secundário. Duas delas estão mais adiantadas, como a demonstrar o seu papel de responsáveis pelos cuidados de

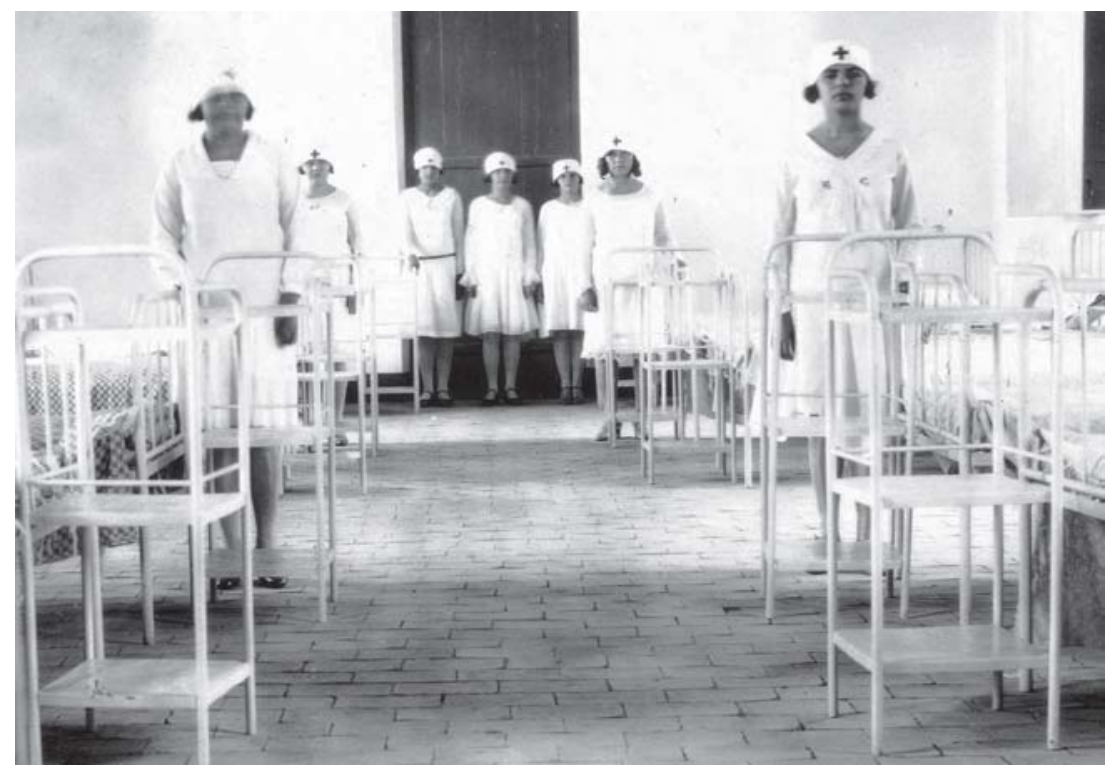

Figura 6 - Enfermeiras no Hospital de São Gonçalo. Sem autoria; sem data. [CLP_SA_HSG_50] 
saúde. Enfermeiras empertigadas, uniformes bem cuidados (notese o chapéu). Não há pacientes, ainda - mas estava tudo ali, para atender as necessidades da região. Poderíamos supor que a formação das enfermeiras na imagem, com duas à frente, indica hierarquia, noção de disciplina, porte, conduta, pois não é de se descartar o fato de essas características serem especialmente desejáveis naquele cenário tão organizado e asséptico. A própria composição (sete enfermeiras) para a foto, posada, evoca em certo sentido ordem e organização.

Enfermeiras e professoras foram duas profissões muito valorizadas nos anos 30. Cuidados com o futuro da nação: a saúde do povo e a educação das crianças. Profissões tipicamente femininas, logo entraram no rol das ocupações regulamentadas pelo Ministério do Trabalho. Durante o Estado Novo, as mulheres participaram de manifestações públicas oficiais, uniformizadas como agentes de saúde ou como normalistas, futuras professoras.

A Figura 6 é o complemento para as fotos em ambientes externos, predominantes na coleção. Se enfermeiras e normalistas são valorizadas, o seu correspondente são as crianças, e praticamente todas as imagens da subsérie as incluem. Tal aspecto, como já discutimos, parece corporificar uma predileção de Luiz Palmier. Talvez por sua especialidade médica, neonatologia e pediatria, praticamente todas as fotos da coleção incluem crianças. Seu projeto de modernidade passava pelo zelo à saúde infantil, não somente por sua consonância com relação aos programas sociais federais, mas também por seu acalentado sonho de transformar os hábitos da comunidade por meio da educação sanitária e das noções medicinais para prevenção de doenças.

\section{Considerações finais}

O conjunto de imagens trabalhadas neste artigo coloca em evidência dois personagens: uma instituição e um indivíduo. O Hospital de São Gonçalo definiu-se, nos primeiros anos de seu funcionamento, como marco de um município moderno. Cumpriu sua finalidade, socialmente demarcada e reverenciada, e assim, interferiu na história da cidade. A vida pública de Luiz Palmier como médico, político e intelectual também chamou a atenção para a especificidade das experiências vividas pelo município. Os dois personagens foram parte ativa da história da cidade, num duplo viés: ora construídos por ela, ora construindo-a.

Em primeiro lugar, portanto, nosso objetivo era sublinhar os contornos de uma experiência 'local'. Ao fazê-lo, em vez de apostar em uma escrita ufanista, projetando o local como um valor superior para admiração e valorização da 'pequena pátria' - ao estilo recorrente de uma historiografia e de um memorialismo ufanista -, 
pretendemos elaborar uma história local como a costura de retalhos de processos de identificação dos sujeitos envolvidos. O procedimento não significa uma simplificação dos aspectos da trama social. $\mathrm{O}$ local, alçado a categoria central de análise, pode vir a constituir uma nova densidade no quadro de interdependências entre agentes e fatores constitutivos de determinadas experiências históricas então eleitas pela lupa do historiador. Ao deslocar o foco da história nacional, buscamos evidenciar a peculiaridade da experiência local. Olhar para esta, por sua vez, é um exercício de busca por apropriações e representações também presentes em escalas mais amplas, de modo a gerar melhor compreensão da sociedade gonçalense.

Estabelecendo as bases da política de saúde local, o Hospital corporifica os contornos de uma política administrativa com relação às questões sanitárias mais amplas, personalizadas pela figura de Luiz Palmier, em um momento histórico em que as ações na área de saúde se faziam presentes nacionalmente enquanto estratégias de condução governamental. (Araújo, 2004, p.47)

Em segundo lugar, pretendemos realçar o uso das imagens como forma de gerar novos efeitos de conhecimento. Acreditamos que a pesquisa histórica baseada em registros fotográficos, considerando as especificidades das configurações sociotemporais, é campo bastante fértil para desenvolver novas percepções e habilidades. A fotografia figura entre os vestígios do passado que permitem o alargamento da noção de documento, há muito proposta para o ofício do historiador.

As fotografias da subsérie Hospital de São Gonçalo corporificam não somente a imagem de uma instituição de vanguarda em seu tempo. Elas projetam e concretizam os ideais de progresso e modernidade consoantes com o ambiente político e intelectual nas décadas de 1930 e 1940. E assim o fazem porque as imagens promovem um impacto visual que estabelece relações, criando afinidades por parte do espectador e resultando na produção não apenas de sentidos, mas também de 'sentimentos'.

\section{NOTAS}

${ }^{1}$ As imagens da Coleção Luiz Palmier estão disponíveis em www.historiadesaogoncalo.pro.br.

2 Esta fotografia também foi publicada no jornal O Estado em 23 ago.1938, com a seguinte legenda: “Na escadaria do Hospital. Grupo de pessoas que tomaram parte nas solenidades da inauguração. Médicos, diretores, conselheiros, damas de caridade, associados e funcionários do Hospital."

3 Segundo Luiz Palmier (1940, p.150, 215), a nova ala foi denominada Ana Jonkopings de Carvalho. O coronel Antônio Jonkopings de Carvalho havia sido eleito presidente da Câmara Municipal de São Gonçalo em 1915 e desfrutou, "na alta sociedade, nos meios políticos e da administração, do mais justo respeito, prestígio e admiração".

${ }^{4}$ Fundado com o nome de Patronato de Menores Abandonados, foi a mais antiga instituição filantrópica do município. Inspirada nas escolas técnicas norte-americanas e belgas, possuía cursos profissionalizantes de carpintaria, sapataria e alfaiataria. Sua banda acompanhava tradicionalmente as solenidades municipais. 
5 É freqüente, na atual historiografia, considerar que as realizações dos anos 30 do século XX foram desdobramentos das inquietações formuladas logo após a Primeira Guerra Mundial. Entre a extensa bibliografia, vale lembrar o já clássico texto de Antonio Candido (1980).

6 Por certo é sempre possível pensar em outras possibilidades. A disposição da foto poderia simplesmente corresponder, por exemplo, a uma ordem de altura das pessoas, o que justificaria as crianças na frente, mas não as mulheres. Daí defendermos que tal disposição revela elementos simbólicos fortemente valorizados pelos personagens da época.

7 Em 1933 o Ministério patrocinou a Conferência Nacional de Proteção à Infância, que reuniu delegados de todo o país para discutir teses sobre a criação de centros de puericultura, organização e administração de serviços de higiene em geral e higiene escolar em particular. Logo em seguida, em 1934, o Ministério da Educação e da Saúde Pública criou a Diretoria de Proteção à Maternidade e à Infância (Sousa, 2000; Hochman, 1993).

8 Atualmente, o Hospital é denominado Luiz Palmier.

9 A coleção Luiz Palmier tem, por exemplo, um álbum de recortes de jornal meticulosamente confeccionado por seu titular, no qual encontram-se várias fotografias da coleção.

10 John Gaddis (2003, p.60-65) apresenta esses três procedimentos (conectar o real, representar, persuadir) para o estabelecimento de métodos científicos e persuasivos, sejam eles desenvolvidos pelo historiador, pelo biólogo ou pelo alfaiate.

11 A praça inaugurada pelo prefeito Miguelote Viana foi denominada Cinco de Julho, uma homenagem ao movimento tenentista.

12 Quando foi inaugurado o biotério, em 1941, Armando Leão Ferreira, recém-empossado diretor do Hospital, afirmou tratar-se do "primeiro estabelecimento científico, anexo e parte integrante de um hospital, a ser inaugurado no Estado do Rio de Janeiro" (Hochman, 2001). O biotério seria um campo de experimentação científica, fonte de abastecimento de soros e vacinas, objetivando o diagnóstico e o acompanhamento de endemias como a tuberculose e a malária.

\section{REFERÊNCIAS BIBLIOGRÁFICAS}

Alvarez, Maurício 1991

Araújo, Marcelo da Silva 2004

Barthes, Roland 2000

Barthes, Roland 1984

Benjamin, Walter 2000

Benjamin, Walter 1994

Candido, Antonio 1980

Dubois, Philippe 1992

Gaddis, John Lewis 2003

Hochman, Gilberto 2001
Arquitetura monumental e vontade de potência.

Rio de Janeiro: Oficina Letras \& Artes.

Construindo narrativas: o Hospital de São Gonçalo nas fotografias de Luiz Palmier - 1931-1942. Trabalho de conclusão de curso (Graduação em História) - Uerj, São Gonçalo.

A mensagem fotográfica. In: Lima, Luís Costa (Org.). Teoria da cultura de massa. 5.ed. São Paulo: Paz e Terra.

A câmara clara: nota sobre a fotografia. 3.ed. Rio de Janeiro: Nova Fronteira.

A obra de arte na época de sua reprodutibilidade técnica. In: Lima, Luís Costa (Org.). Teoria da cultura de massa. 5.ed. São Paulo: Paz e Terra.

Pequena história da fotografia: magia e técnica, arte e política. São Paulo: Brasiliense.

A Revolução de 30 e a cultura. In: Candido, Antonio. A educação pela noite e outros ensaios. São Paulo: Ática.

$O$ acto fotográfico.

Lisboa: Veja.

Paisagens da história: como os historiadores mapeiam o passado. Rio de Janeiro: Campus.

A saúde pública em tempos de Capanema: continuidades e inovações. In: Bomeny, Helena (Org.). Constelação Capanema: intelectuais e política. Rio de Janeiro: Ed. FGV. 


Hochman, Gilberto
1993
Kossoy, Boris
1993
Kossoy, Boris
1989
Lacerda, Aline Lopes de
1994
Le Goff, Jacques
1984
Machado, Fábio Nunes
2002

Mauad, Ana Maria 2004 Mauad, Ana Maria
2000

Mauad, Ana Maria
1996
Morais, Frederico
1998
Oliveira Junior, Antônio
2000

Palmier, Luiz 1940

Palmier, Luiz 5 out. 1920

Pomian, Krzysztof 1984

Reznik, Luís (Org.) 2003

Saneamento... 1935

Silva, Renata A. dos Santos 1998

Sousa, Cynthia Pereira de 2000
Regulando os efeitos da interdependência: sobre as relações entre saúde pública e construção do Estado (Brasil 1910-1930). Estudos históricos, Rio de Janeiro, v.11, p.40-61.

Estética, memória e ideologia fotográficas. Acervo, Rio de Janeiro, v.6, n.12, p.13-24.

Fotografia e história. São Paulo: Ática.

A 'obra getuliana' ou como as imagens comemoram o regime. Estudos históricos, Rio de Janeiro, v.7, n.14, p.241-263.

Documento/monumento. In: Romano, Ruggiero (Org.). Enciclopédia Einaudi. Lisboa: Imprensa Nacional. (Memória e História, 1). p.95-106.

A atuação do poder público na construção do espaço urbano gonçalense entre os anos 1920-1950. Monografia (Graduação em História) - Universidade do Estado do Rio de Janeiro, São Gonçalo.

Criação/revelação, ou mera reprodução? Fotografia e fotógrafos na primeira metade do século XX. In: Pereira, S. Gomes; Conduru, Roberto (Ed.). Colóquio de História da Arte, 23. Anais... Rio de Janeiro: CBHA; UFRJ; Uerj.

Na mira do fotógrafo: o Rio de Janeiro e seus espaços através das lentes de Gutierrez. Anais do Museu Histórico Nacional, Rio de Janeiro, v.32, p.135-153.

Fotografia e história - interfaces. Tempo, Niterói, v.2, n.1, p.16-46.

Arte é o que eu e você chamamos arte: 801 definições sobre arte e o sistema de arte. Rio de Janeiro: Record.

A luz do social nas imagens: fragmentos teóricos na fotografia de documentação social. Anais do Museu Histórico Nacional, Rio de Janeiro, v.32, p.51-70.

São Gonçalo - cinqüentenário: história, geografia, estatística.

Rio de Janeiro: Serviços Gráficos do IBGE.

São Gonçalo do futuro.

A Gazeta, São Gonçalo.

Coleção. In: Romano, Ruggiero (Org.). Enciclopédia Einaudi. Lisboa: Imprensa Nacional. (Memória e História, 1). p.51-86.

O intelectual e a cidade: Luiz Palmier e a conformação de uma São Gonçalo moderna. Rio de Janeiro: Ed. Uerj.

Saneamento da Baixada - um serviço de combate à malária no Hospital de São Gonçalo. O Estado, São Gonçalo, 5 set. 1935.

Homens de 'pequenas profissões': a fotografia na construção de representações sobre o trabalho ambulante na cidade do Rio de Janeiro do início do século XX. Dissertação (Mestrado) - Departamento de História, Universidade Federal Fluminense, Niterói.

Saúde, educação e trabalho de crianças e jovens: a política social de Getúlio Vargas. In: Gomes, Ângela de Castro (Org.). Capanema: o ministro e seu ministério. Rio de Janeiro: Ed. FGV. 